\title{
GOLD2012 - 6th International Conference on Gold Science, Technology and its Applications, September 5-8, 2012, Keio Plaza Hotel, Tokyo, Japan
}

\author{
Takashi Takei
}

Published online: 20 July 2012

(C) The Author(s) 2012. This article is published with open access at SpringerLink.com

The organizers of the 6th International Conference on Gold Science, Technology and its Applications are pleased to announce the invited speakers and sponsors.

Plenary
A. Stephen K. Hashmi (University of Heidelberg)
New Options with New Ligands in Homogeneous Gold Catalysis

Hans-Joachim Freund (Fritz Haber Institute of the Max Planck Society)

The Surface Science of Supported Au Nanoparticles and its Relation to Catalysis

Vincent M. Rotello (University of Massachusetts)

Gold Nanoparticles in Biomedicine: Therapeutics and Diagnostics

\section{Tutorial}

Antonio M. Echavarren (Institute of Chemical Research of Catalonia)

Molecular Complexity through Gold Catalysis

Mathias Brust (University of Liverpool)

Monolayer Protected Clusters of Gold: Building Blocks, Functional Materials, Macromolecules, Biomedical Tools and more

\section{T. Takei $(\bowtie)$}

Department of Applied Chemistry, Graduate School of Urban

Environmental Sciences, Tokyo Metropolitan University,

1-1 Minami-ohsawa, Hachioji,

Tokyo 192-0397, Japan

e-mail: goldcat@tmu.ac.jp
Ross Hatton (Molecular Solar Ltd.)

Nano-structured gold window electrodes and their application in organic photovoltaics

Kohmei Halada (National Institute for Materials Science)

Science and Technology on Elements

Keynote

Didier Astruc (University of Bordeaux I)

Engineering of Gold Nanoparticles towards Biomedical Applications

F. Dean Toste (University of California, Berkeley) Enantioselective Catalysis with Gold(I) Complexes

Graham J. Hutchings (Cardiff University)

Catalysis using supported gold and gold palladium nanoparticles

Hannu Häkkinen (University of Jyväskylä)

Nanoscale Gold in Passive and Active Forms: Lessons and Prospects from Computational Studies

Jason S. McPherson (Mintek)

Current and Potential Commercial Applications of Gold Catalysts

Jonathan Heddle (RIKEN)

A gold Nanoparticle-Catalysed Artificial Protein Capsid

Lai Sheng Wang (Brown University)

Size-selected Gold Clusters: Structure Evolution and O2 Activation 
Laura Prati (University of Milan)

Gold Catalyzed Liquid Phase Reaction: The Active Role of the Solvent

Michael J. Natan (Cabot Security Materials Inc.)

Optimizing the Antenna for Nanoparticle SERS

Misao Itouga (RIKEN)/Seiji Nakatsuka (DOWA HOLDINGS CO., LTD.)

Making a discovery through bryological science

Tao Zhang (Dalian Institute of Chemical Physics)

Design, Synthesis and Structure Changes of Au-Ag and Au$\mathrm{Cu}$ Nanoparticle Catalysts

Toshiharu Teranishi (Kyoto University)

Nanoplasmonics in Polyhedral Gold Nanoparticle Assemblies

Uzi Landman (Georgia Institute of Technology)

When Small is Different: Surface-Supported and Gas-Phase Gold Nanocatalysis

Yi Ding (Shandong University)

Catalysis and Electrocatalysis by Nanoporous Gold
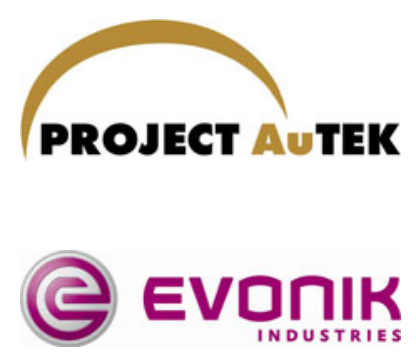

BBInTERNATIONAL

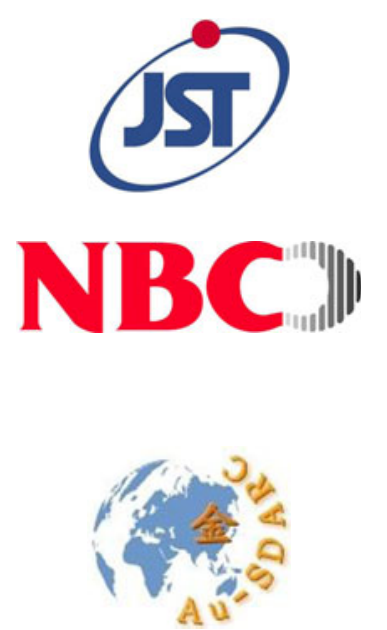

Peter Bishop (Johnson Matthey)

Gold Nanoparticles and their use in Functional Films and Catalytic Transformations

Thompson memorial

Catherine Louis (Pierre and Marie Curie University)

Gold Nanoparticles in the Past: Their First Uses Before the Nanotechnology Era

\section{JST Crest symposium}

Working Mechanism of Gold Catalysts and Their Applications to Green Chemistry

John T. Yates Jr. (University of Virginia)

Infrared Studies of Nanoparticle Au Oxidation Catalysis at Low Temperatures

Bruce C. Gates (University of California, Davis)

Kinetic Studies of CO Oxidation over Nanoparticle Gold Catalysts (tentative)

Itsuo Toshima (Former Representative of Asian Office of World Gold Council)

World Gold Market: Present and Future (tentative)
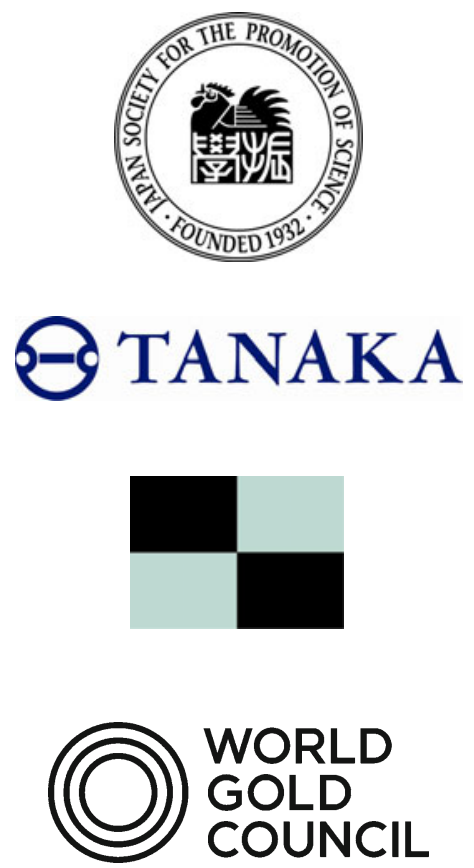

Open Access This article is distributed under the terms of the Creative Commons Attribution License which permits any use, distribution and reproduction in any medium, provided the original author(s) and source are credited. 